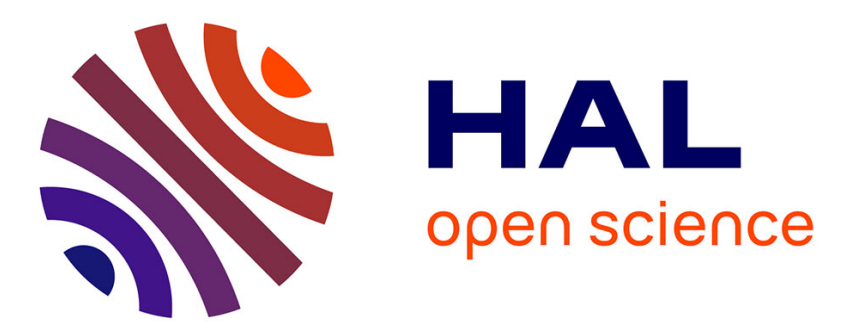

\title{
On the symmetrical role of cross-slip of screw dislocations and climb of edge dislocations as recovery processes controlling high-temperature creep
}

\author{
J.P. Poirier
}

\section{- To cite this version:}

J.P. Poirier. On the symmetrical role of cross-slip of screw dislocations and climb of edge dislocations as recovery processes controlling high-temperature creep. Revue de Physique Appliquée, 1976, 11 (6), pp.731-738. 10.1051/rphysap:01976001106073100 . jpa-00244107

\section{HAL Id: jpa-00244107 https://hal.science/jpa-00244107}

Submitted on 1 Jan 1976

HAL is a multi-disciplinary open access archive for the deposit and dissemination of scientific research documents, whether they are published or not. The documents may come from teaching and research institutions in France or abroad, or from public or private research centers.
L'archive ouverte pluridisciplinaire HAL, est destinée au dépôt et à la diffusion de documents scientifiques de niveau recherche, publiés ou non, émanant des établissements d'enseignement et de recherche français ou étrangers, des laboratoires publics ou privés. 


\author{
Classification \\ Physics Abstracts \\ $7.223-7.166-7.630$
}

\title{
ON THE SYMMETRICAL ROLE OF CROSS-SLIP OF SCREW DISLOCATIONS AND CLIMB OF EDGE DISLOCATIONS AS RECOVERY PROCESSES CONTROLLING HIGH-TEMPERATURE CREEP
}

\author{
J. P. POIRIER \\ Centre d'Etudes Nucléaires de Saclay \\ Section de Recherches de Métallurgie Physique, Boîte Postale no 2, 91190 Gif-sur-Yvette, France
}

(Reçu le 4 juin 1976, accepté le 8 juillet 1976)

Résumé. - On propose un modèle général du fluage contrôlé par la restauration, fondé sur l'introduction du glissement dévié des dislocations vis comme mécanisme de restauration, à égalité et en parallèle avec la montée des dislocations coin.

A partir d'hypothèses simples, on obtient l'équation de comportement :

$$
\dot{\varepsilon}=\dot{\varepsilon}_{0, \mathrm{SD}}\left(\frac{\sigma}{\mu}\right)^{3} \exp -\frac{Q_{\mathrm{SD}}}{k T}+\dot{\varepsilon}_{0, \mathrm{cs}}\left(\frac{\sigma}{\mu}\right)^{2} \exp -\frac{Q_{\mathrm{CS}}\left(\sigma, \gamma_{\mathrm{F}}\right)}{k T} .
$$

La montée et le glissement dévié sont prédominants dans différents domaines de $T$ et $\sigma$, suivant l'importance relative des énergies d'activation pour l'autodiffusion $Q_{\mathrm{SD}}$ et le glissement dévié $Q_{\text {cs }}(\sigma)$. La vitesse'de fluage ne suit pas une loi puissance en contrainte, sauf si la montée domine et l'existence d'un régime de transition peut faire trouver des exposants de contrainte apparents élevés sans signification physique.

Les résultats expérimentaux publiés sont compatibles avec ce modèle, à titre d'exemple on examine le cas du cuivre et on montre que le domaine de faible énergie d'activation peut être contrôlé par le glissement dévié. La présente approche pourrait être utilisée dans des problèmes tels que celui de l'influence de l'énergie de faute d'empilement sur la vitesse de fluage ou celui du fluage des solutions solides.

Abstract. - A general model for high-temperature recovery-controlled creep is proposed. Cross slip of screw dislocations is introduced on an equal footing with climb of edge dislocations as a recovery process : cross slip and climb operate as two parallel concurrent mechanisms controlling the creep rate.

A constitutive equation is derived from șimple assumptions :

$$
\dot{\varepsilon}=\dot{\varepsilon}_{0, \mathrm{SD}}\left(\frac{\sigma}{\mu}\right)^{3} \exp -\frac{Q_{\mathrm{SD}}}{k T}+\dot{\varepsilon}_{0, \mathrm{Cs}}\left(\frac{\sigma}{\mu}\right)^{2} \exp -\frac{Q_{\mathrm{CS}}\left(\sigma, \gamma_{\mathrm{F}}\right)}{k T} .
$$

Climb and cross slip are dominant in different domains of $T$ and $\sigma$ according to the relative magnitudes of the activation energies for self-diffusion $Q_{\mathrm{SD}}$ and cross slip $Q_{\mathrm{cs}}(\sigma)$. The stress dependence of $\dot{\varepsilon}$ does not follow a power law except when climb is dominant, and intermediate values of apparent stress exponents are attributed to the existence of a transition domain.

The published experimental evidence is compatible with this model ; the case of copper is reviewed as an example and it is shown that the low activation energy domain can be controlled by cross slip. The present approach is relevant to such problems as the influence of the stacking-fault energy on the creep rate or the creep of solid-solution alloys.

1. Introduction. - There is a wide consensus to ascribe the secondary, so-called steady-state stage of high-temperature creep at constant stress to a balance between work-hardening and recovery. Numerous creep models have been proposed for pure metals and, although they slightly differ in the description of the recovery process, they practically all concur in the assumption that recovery takes place by diffusioncontrolled climb of edge dislocation segments, arrang- ed in pile-ups, multipoles, networks or tilt walls according to the model $[1,2]$. A recent review of the literature devoted to creep [3] has convinced the present author that the equally important recovery process : cross slip of screw dislocations, has been given lip service only. The reason for this neglect obviously lies in the fact that self-diffusion is a much better known process than is cross-slip. Thus, values of activation energies for creep can be compared to 
published values of activation energies for self-diffusion, whereas no such comparison is possible for cross slip. It is therefore very seldom that cross-slip has been proposed as a controlling mechanism for creep and only in cases (e. g. aluminium) where a model could be found for it in the literature.

The purpose of this paper is to bring cross-slip back into focus as a general recovery mechanism, possibly as important as climb of edge dislocations. It will be shown that cross-slip of screw dislocations and climb of edge dislocations may act as parallel-concurrent recovery mechanisms and that the extant evidence by no means uniquely points to climb. A tentative model for climb and cross-slip-controlled creep will be sketched. Due to our utter lack of knowledge of the activation quantities for cross slip and to the unavoidably great number of simplifying assumptions that is the rule with this type of model, it will not be attempted to make it quantitative. However, a satisfying symmetry between screw and edge portions of loops can be brought into the picture of recovery and it may be possible to look in this direction for an answer to problems that arise in many instances, such as the variation with stress or temperature of activation energies for creep or the existence of stress exponents of the strain rate too high to be compatible with a climb alone theory. The available literature on the creep of some fcc and hcp metals will be examined in this light. Finally, a few possible consequences of this approach in two areas will be looked into: the influence of stacking fault energy on creep rate and the Sherby-Burke classification of solid solution alloys.

2. A simple model for high-temperature creep by climb and cross-slip controlled glide. - Let us consider a dislocation loop - rectangular for the sake of simplicity - we will assume that the contribution of this loop to the creep strain is due to the glide of its edge and screw portions and that both these portions are respectively blocked against similar portions of other loops lying in neighboring planes (Fig. 1). This

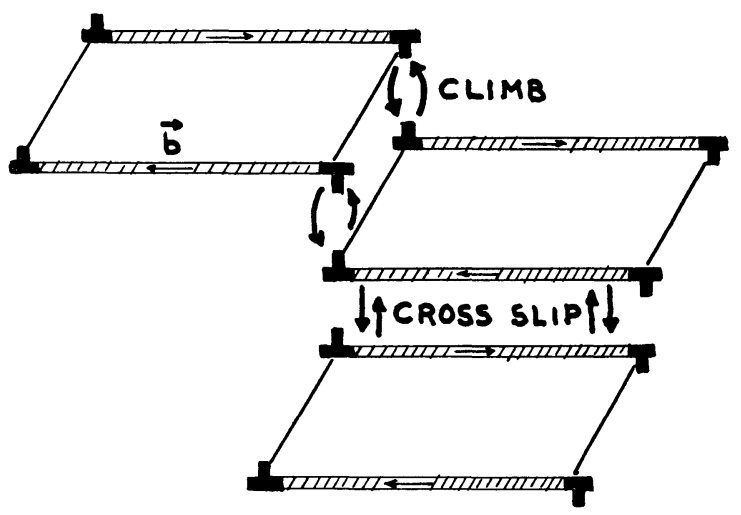

FIG. 1. - Rectangular dislocation loops mutually blocked at their edge portions and split screw portions (hatched). The unblocking or annihilation, is possible by climb for the former and by cross slip for the latter. hypothesis is much the same as the one proposed by Weertman [4] as far as edge segments are concerned but differs from it in assuming that the screw portions can also be blocked. Indeed in every conceivable case where screw dislocations glide they are extended and even if the width of the stacking fault is extremely small, so that it is preferable to speak of a flattened core, the dissociation is very effective in constraining the screw dislocation to glide in only one plane. Screw dislocations can therefore be blocked just as edge dislocations and, if there is a cross-slip plane available, they can be unblocked by thermally activated cross slip just as edge dislocation are unblocked by climb.

The assumption of mutually blocked rectangular loops has been used only to visualize the blocking of edge and screw segments and is not essential to our unsophisticated model. We could, for instance, as well assume that edge and screw dislocations are emitted and absorbed at tilt and twist subgrain boundaries. We will therefore consider only a density $o$ mobile edge dislocations : $\rho_{\mathrm{E}}$ and a density of mobile screw dislocation : $\rho_{\mathrm{S}}$.

Let $\Delta L_{\mathrm{E}}$ and $\Delta L_{\mathrm{S}}$ be the lengths swept respectively by the edge and screw dislocations of Burgers vector $\mathbf{b}$ after their unblocking by climb and cross-slip, and let $\varepsilon_{\mathrm{E}}$ and $\varepsilon_{\mathrm{S}}$ be the contributions to the total creep strain of the edge and screw dislocations :

$$
\varepsilon=\varepsilon_{\mathrm{E}}+\varepsilon_{\mathrm{S}} .
$$

The climb-controlled glide of edge segments and the cross-slip-controlled glide of screw segments are clearly independent, parallel-concurrent mechanisms [5].

We have therefore :

$$
\dot{\varepsilon}=\dot{\varepsilon}_{\mathrm{E}}+\dot{\varepsilon}_{\mathrm{S}} \text {. }
$$

Let $t_{\mathrm{E}}$ and $t_{\mathrm{S}}$ be the average time taken for unblocking an edge or a screw dislocation and let $t_{\mathrm{g}}$ be the time taken to sweep by glide $\Delta L_{\mathrm{E}}$ and $\Delta L_{\mathrm{S}}$.

Assuming that glide does not control creep, i. e. :

$$
t_{\mathrm{g}} \ll t_{\mathrm{E}} \quad \text { and } \quad t_{\mathrm{g}} \ll t_{\mathrm{S}} \text {. }
$$

Eq. (2) can be written :

$$
\dot{\varepsilon}=\frac{\varepsilon_{\mathrm{E}}}{t_{\mathrm{E}}}+\frac{\varepsilon_{\mathrm{S}}}{t_{\mathrm{S}}}
$$

or :

$$
\dot{\varepsilon}=\rho_{\mathrm{E}} \mathbf{b} \frac{\Delta L_{\mathrm{E}}}{t_{\mathrm{E}}}+\rho_{\mathrm{S}} \mathbf{b} \frac{\Delta L_{\mathrm{S}}}{t_{\mathrm{S}}}
$$

Now, we have :

i)

$$
t_{\mathrm{E}}=\frac{h}{v_{\mathrm{c}}}
$$

where : $h$ is the distance to be climbed by edge dislo- 
cations to escape or annihilate, and $V_{\mathrm{c}}$ is the climb velocity which can be written [6] :

$$
v_{\mathrm{c}}=\frac{D \Omega \sigma}{k T \lambda}
$$

with : $\Omega$, the atomic volume,

$\sigma$, the applied stress,

$\lambda$, a length characteristic of the geometry of the diffusion of vacancies between sources and sinks

$$
D=D_{0} \exp -\left(\frac{Q_{\mathrm{SD}}}{k T}\right)
$$

is the self-diffusion coefficient and $Q_{\mathrm{SD}}$ the activation energy for self-diffusion. We assume here that climb is diffusion-controlled, i. e. the dislocations are saturated in jogs.

ii) Cross-slip is controlled by the thermally activated constriction of the stacking fault and recombination of the partial dislocations ; we have in general :

$$
t_{\mathrm{S}}=\beta \exp \frac{Q_{\mathrm{CS}}\left(\sigma, \gamma_{\mathrm{F}}\right)}{k T}
$$

where $\beta$ is a constant, and $Q_{\mathrm{cs}}$ is the activation energy for cross slip, a function of the applied stress and the stacking fault energy.

iii) Whatever the chosen spatial repartition of dislocations (loops, Frank network or straight segments), as long as they are assumed to be in equilibrium in the internal stress field $\sigma_{\mathrm{i}}$ of the repartition and that there is no accumulation between cell walls, the dislocation density must be written, for purely geometrical reasons :

$$
\rho \propto L^{-2}
$$

where $L$ is the equilibrium distance between dislocations.

As the stress field of a dislocation varies as $1 / r$, we have :

$$
\sigma_{\mathbf{i}} \propto \frac{\mu \mathbf{b}}{L}
$$

We will assume that in the quasi steady-state creep regime we have : $\sigma=\sigma_{\mathrm{i}}$ and that the dislocation densities $\rho_{\mathrm{E}}$ and $\sigma_{\mathrm{S}}$ are constant ; we can then write :

$$
\begin{gathered}
\rho_{\mathrm{E}}=\frac{\alpha_{\mathrm{E}}}{b^{2}}\left(\begin{array}{l}
\sigma \\
\frac{\mu}{\mu}
\end{array}\right)^{2} \\
\rho_{\mathrm{S}}=\frac{\alpha_{\mathrm{S}}}{b^{2}}\left(\frac{\sigma}{\mu}\right)^{2}
\end{gathered}
$$

where $b^{2}$ has been introduced to keep the expression dimensionally correct and $\alpha_{\mathrm{E}}$ and $\alpha_{\mathrm{S}}$ are dimensionless constants of geometrical and statistical origin.
The general form of the constitutive equation for creep can be written from (4), (5), (6), (7), (8), (11) :

$$
\begin{aligned}
\dot{\varepsilon}=\alpha_{\mathrm{E}} \frac{\Delta L_{\mathrm{E}}}{\mathrm{b} h} \cdot \frac{\sigma}{\lambda} & \cdot \frac{\Omega D_{0}}{k T} \frac{\sigma^{2}}{\mu^{2}} \exp -\left(\frac{Q_{\mathrm{SD}}}{k T}\right)+ \\
& +\alpha_{\mathrm{S}} \frac{\Delta L_{\mathrm{S}}}{\mathbf{b} \beta} \frac{\sigma^{2}}{\mu^{2}} \exp -\left[\frac{Q_{\mathrm{CS}}\left(\sigma, \gamma_{\mathrm{F}}\right)}{k T}\right]
\end{aligned}
$$

or, more synthetically :

$$
\begin{aligned}
\dot{\varepsilon}=\dot{\varepsilon}_{0, \mathrm{SD}}\left(\frac{\sigma}{\mu}\right)^{3} & \exp -\left(\frac{Q_{\mathrm{SD}}}{k T}\right)+ \\
& +\dot{\varepsilon}_{0, \mathrm{CS}}\left(\frac{\sigma}{\mu}\right)^{2} \exp -\left(\frac{Q_{\mathrm{CS}}\left(\sigma, \gamma_{\mathrm{F}}\right)}{k T}\right) .
\end{aligned}
$$

3. Discussion. - Several points may be noted about equation (13) :

i) Since we have considered climb and cross-slip as parallel-concurrent mechanisms the total creep rate appears as a sum of two terms. This approach is identical to the one taken by Gifkins [5] but, whereas this author had considered two power-law terms with different stress exponents, we have one power-law term for the climb-controlled contribution and one exponential term for the cross-slip-controlled contribution, with a different activation energy. The qualitative conclusions are obviously the same as previously drawn by Gifkins :

- The Arrhenius plot $\ln \dot{\varepsilon}$ vs $1 / T$ is not a straight line over the whole temperature range. The mechanism with the higher activation energy is preponderant at higher temperatures and the one with the lower activation energy, at lower temperatures. There is a transition region where it is possible to find a value for the activation energy of the creep rate, in a limited temperature range, but this value has, of course, no physical meaning. In the same way, it is physically meaningless to attribute the transition region to the operation of a third creep mechanism.

- The strain rate vs stress logarithmic plot is not a straight line either and the values of the stress exponent found in a limited stress domain in the transition region do not correspond to a particular creep mechanism.

ii) In the general case of two parallel-concurrent mechanisms, the apparent activation energy may depend on stress as well as on temperature. In the same way, the apparent stress sensitivity of the strain rate may depend on temperature as well as on stress. To better separate these dependences, it is interesting to resort to a 3-dimensional representation of the surface $\ln \dot{\varepsilon}=f(\ln \sigma, 1 / T)$ whose sections by $1 / T=$ const. planes will give strain rate vs stress plots and section by $\ln \sigma=$ const. planes, Arrhenius plots. Such representations are given figure 2 in the cases where the activation energy for cross-slip is lower or higher than the activation energy for self-diffusion. 


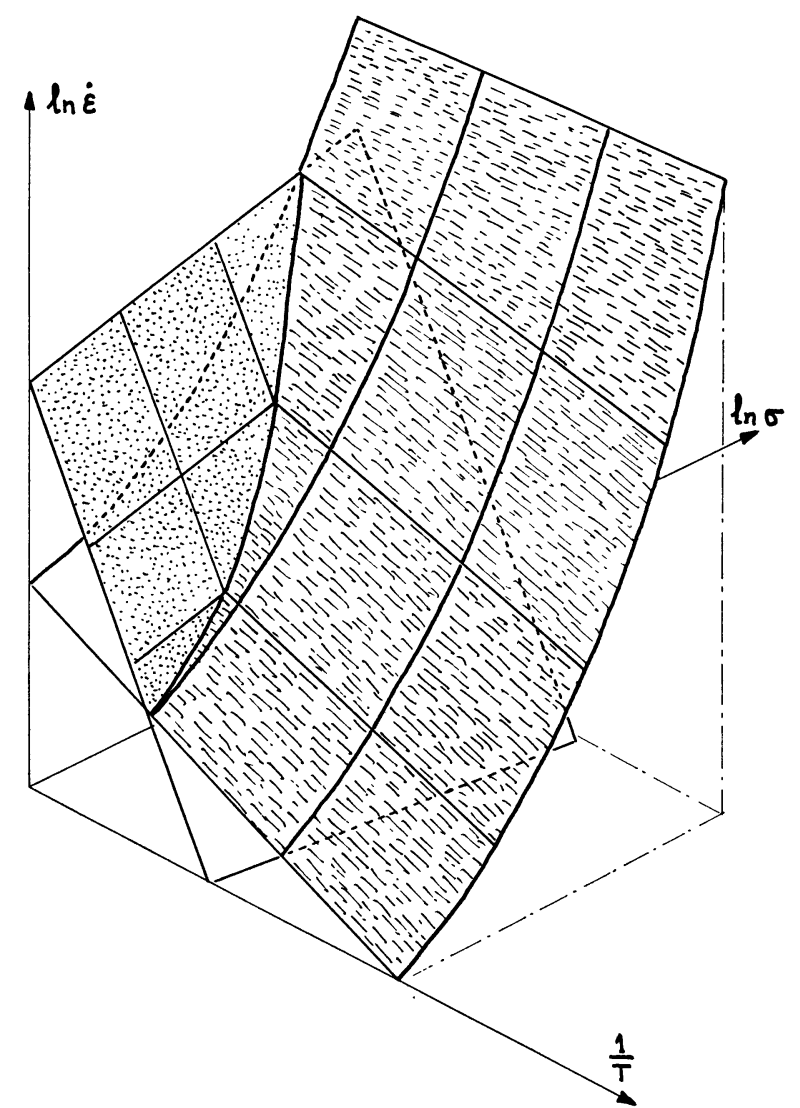

(a)

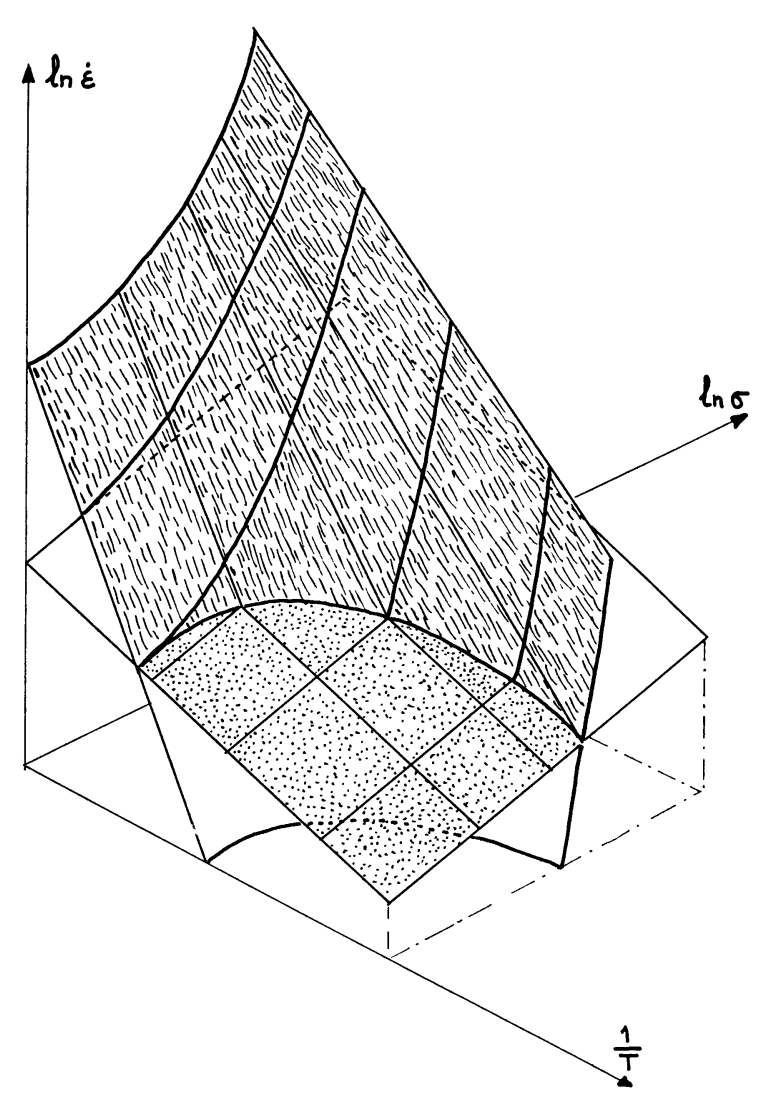

(b)

FIG. 2. $-\ln \dot{\varepsilon}=f(\ln \sigma, 1 / T)$ surfaces. The portion of the surface corresponding to conditions where climb controls is a plane (stippled). The transition region is not represented. The sections by $\ln \dot{\varepsilon}-\frac{1}{T}$ planes (Arrhenius curves) and by $\ln \dot{\varepsilon}-\ln \sigma$ curves are represented. Note that in the cross-slip-controlled region $Q_{\mathrm{CS}}$ decreases as $\sigma$ increases and $\partial \ln \dot{\varepsilon} / \partial \ln \sigma$ increases as $T$ decreases. a) Case where $Q_{\mathrm{Cs}}<Q_{\mathrm{SD}}$. The climb-controlled region is situated at higher temperatures. $b$ ) Case where $Q_{\text {Cs }}>Q_{\text {SD. }}$. The climb-controlled region is situated at lower temperatures.

iii) Before discussing in more detail equation (13), let us state again that it applies only to creep at high or intermediate temperatures $\left(T>0.3 T_{\mathrm{m}}\right)$ where climb and/or cross-slip operate as recovery mechanisms.

It is obvious from figure 2 that the $T$ and $\sigma$ domains where climb or cross slip will be predominant depend on the relative magnitude of the activation energies for self-diffusion and cross-slip $Q_{\mathrm{SD}}$ and $Q_{\mathrm{CS}}$. Crossslip being a thermally activated mechanism $Q_{\mathrm{cs}}$ must decrease as the applied stress $\sigma$ increases, but there is every reason for the dependence of $Q_{\mathrm{cs}}$ on $\sigma$ to be extremely complicated, even non-analytical, although approximations may sometines be formulated for low stresses [7]. The extension of the domain where recovery by climb predominates, therefore depends on the following factors :

- The difference between $Q_{\mathrm{SD}}$ and $Q_{\mathrm{CS}}(\sigma=0)$ which among other things depends on the stackingfault energy.

- The dependence of $Q_{\mathrm{cs}}$ on $\sigma$.
- The relative magnitude of the preexponential factors $\dot{\varepsilon}_{0, \mathrm{SD}}$ and $\dot{\varepsilon}_{0, \mathrm{Cs}}$.

There is a priori no reason why climb should necessarily be the dominant recovery mechanism at the higher temperatures.

For the climb-controlled term, we have deduced a power-law dependance with $n=3$ from the simplest physically reasonable assumptions. This is in agreement with the contention that $n=3$ is the most natural stress-exponent [1] and with the results of the analysis of Stocker and Ashby [8]. A stress exponent higher than $n=3$ experimentally determined in a limited stress range, must surely be taken as a clue that climb is not the only recovery process and may not even be dominant. However, there is a possibility that $n$ for the climb-controlled term be a little higher than 3 if pile-ups must be taken into account [1] or if the climb velocity of dislocations does not depend linearly on stress. Thus the present analysis leads to the following conclusions, which we will try to confirm in next section by reviewing some specific cases in the literature : 
a) There is no good theoretical reason, nor is there, in most cases, sufficient experimental evidence to single out climb as the only recovery mechanism operative at high temperatures.

b) The commonly-used analysis consisting of plotting

$$
\frac{\dot{\varepsilon} k T}{D}=\frac{\dot{\varepsilon} k T}{D_{0}} \exp \left(\frac{Q_{\mathrm{SD}}}{k T}\right) \text { vs } \ln \sigma
$$

for experiments at various temperatures and stresses is perfectly valid (although useless) if one is sure that climb is the only (or dominant) recovery process; but to use this analysis to determine the stress exponent and the activation energy $Q$ for steady-state creep is a rather objectionable procedure because of the nature of the circular reasoning involved in assuming beforehand that $Q=Q_{\mathrm{SD}}$. The values of $Q$ and $n$ found in this way may have no physical meaning. The fact that this analysis is widely used in the high temperature creep literature (e. g. [2]) is proof enough that the last remark is not as trite as it may appear.

4. Review of some specific cases. - 4.1 ALUMINIUM. - Aluminium is one of the very few metals for which cross-slip has been specifically mentioned as an active creep mechanism and not as a mere possible mechanism.

The activation energy $Q$ for the creep of aluminium was determined in a large temperature range by Sherby, Lytton and Dorn [9] on polycrystals and Lytton, Shepard and Dorn [10] on single crystals. They found two values for $Q$, one in the high-temperature domain $(Q=35.5 \mathrm{kcal} / \mathrm{mole})$ was equal to a published value of $Q_{\mathrm{SD}}$ and there was accordingly no difficulty in proposing that creep was controlled by climb ; the other value $(Q=28 \mathrm{kcal} / \mathrm{mole})$ corresponded to a lower temperature domain and was ascribed to a cross slip mechanism by Lytton et al. [10]. These results and the corresponding interpretations were confirmed by Dorn and Jaffe [11].

It is of some interest to notice that the interpretation in terms of cross-slip of the lower $Q$ creep regime was essentially based on two facts : the metallographic observation of cross-slip markings on single crystals and the excellent agreement of the value $Q=28 \mathrm{kcal} /$ mole with a theoretical value proposed earlier by Friedel for the activation energy for cross-slip. The expected variation of $Q$ with $\sigma$ was not detectable in the limited range of stresses used.

We may remark that there is a difference of $7500 \mathrm{cal} /$ mole $(\simeq 0.3 \mathrm{eV})$ between the two values of $Q$. This is well within the scatter of published values of $Q_{\text {SD }}$ for many metals, and indeed in most cases, values of $Q$ and $Q_{\mathrm{SD}}$ differing by no more than $0.3 \mathrm{eV}$ have been found in good agreement.

There are grounds to think that the existence of a theoretical value for $Q_{\mathrm{Cs}}$ was determinant for the outcome of the analysis in the case of aluminium. The observation of cross-slip marking was also very important and we may observe here that metallographic observations have seldom been performed on crept single crystals of other metals. Anyway, crossslip might control recovery without contributing to the creep strain and hence producing slip lines.

It is probable that the case of aluminium is not unique and that cross-slip may play an important role in the high temperature creep of other metals. We will now examine in this light the extant experimental evidence for copper and hcp metals.

4.2 COPPER. - The values of $\log _{10} \dot{\varepsilon}$ as a function of $\log _{10} \sigma$ and $1 / T$ for the published creep experiments have been plotted on figure $3[12,13,14,15]$. The values of Pahutova, Čadek and Ryš [16] agree quite well with the others but we have not plotted them for the sake of clarity.

When all the data are seen together it is clear that there is a good agreement between them and that figure 3 corresponds in fact to the projections on the $\log \dot{\varepsilon}-\log \sigma$ and $\log \dot{\varepsilon}-\frac{1}{T}$ planes of a surface similar to the one represented in figure 2, consisting of two regions connected by a gradual transition domain.

The activation energies range from 24 to $30 \mathrm{kcal} /$ mole in the lower temperature region (still above $0.5 T_{\mathrm{m}}$ ) and from 48 to $52 \mathrm{kcal} / \mathrm{mole}$ in the higher temperature region. The existence of a third region at still higher temperatures corresponding to very high activation energies reported by Gilbert and Munson [14] ( $Q=168 \mathrm{kcal} / \mathrm{mole}$ ) seems very dubious since recrystallization is commonly reported to occur in this domain of temperature and stress.

We are clearly faced with a situation analogous to the one of aluminium but its interpretation has proceeded along different lines. Whereas the high activation energy domain is ascribed to self-diffusioncontrolled climb $\left(Q_{\mathrm{SD}}=47 \mathrm{kcal} / \mathrm{mole}\right)$ by all the authors who observed it, there is no consensus about the lower activation energy and various mechanisms were invoked for it (diffusion in dislocations, vacancy migration, etc...). Feltham and Meakin [12] thought of cross slip only to summarily reject it on the grounds that $Q$ was linearly dependent on $\sigma$.

However, cross-slip is well documented in copper and Escaig [7] has calculated the activation energy for cross-slip, to account for the measured value of $\tau_{\text {III }}$, the stress at which stage III begins in constant strain rate experiments.

Escaig's model for the constriction of the fault and the deviation of the dislocation leads to an expression for $Q_{\mathrm{Cs}}$ which depends non-analytically on $\sigma$, but a development to first order is possible for low stresses ( $\sigma<5$ or $6 \mathrm{~kg} / \mathrm{mm}^{2}$ for copper), and the activation energy for cross slip can be written :

$$
Q_{\mathrm{CS}} \simeq \frac{\mu^{2} \mathbf{b}^{4}}{1859 \gamma_{\mathrm{F}}}\left[\ln \frac{2 \sqrt{3} \mu \mathbf{b}}{\gamma_{\mathrm{F}}}\right]^{1 / 2}\left(1-\frac{3 \mathbf{b} \sigma}{\gamma_{\mathrm{F}}}\right)
$$




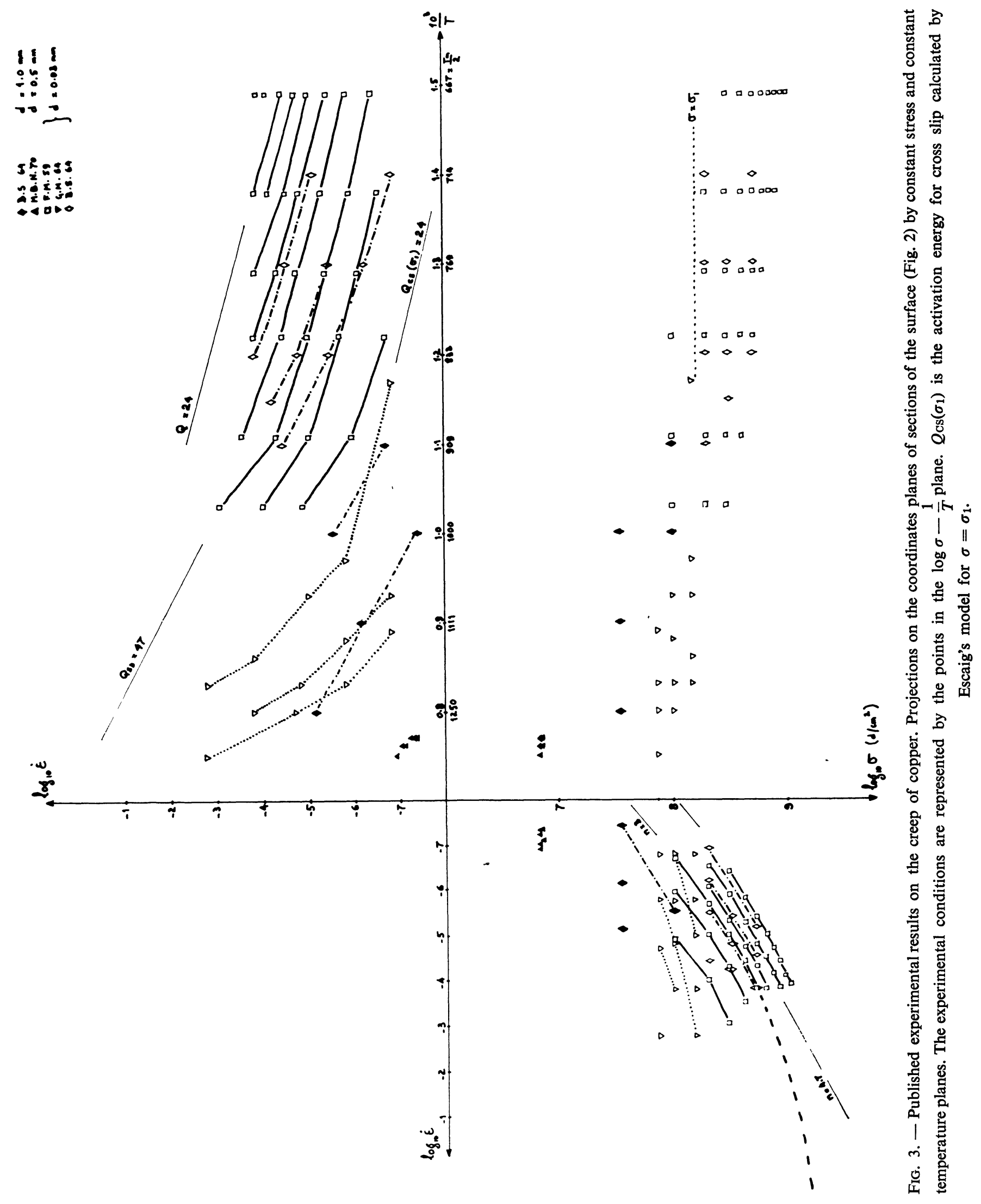


if we take for copper :

$$
\begin{aligned}
& \mu=4.9 \times 10^{11} \mathrm{~d} / \mathrm{cm}^{2} \\
& \text { b }=2.6 \times 10^{-8} \mathrm{~cm} \\
& \gamma_{\mathrm{F}}=40 \mathrm{ergs} / \mathrm{cm}^{2}
\end{aligned}
$$

we obtain :

$$
Q_{\mathrm{cs}}^{\mathrm{ergs}}=2.6 \times 10^{-12}\left(1-1.95 \times 10^{-9} \sigma\right) .
$$

A value of $Q_{\text {cs }}$ equal to the activation energy of the creep-rate at lower temperatures : $Q=24 \mathrm{kcal} / \mathrm{mole}$ is obtained for an applied stress $\sigma_{1}=1.86 \mathrm{~kg} / \mathrm{mm}^{2}$, in excellent agreement with the lower applied stresses in the range where $Q=24 \mathrm{kcal} / \mathrm{mole}$ (Fig. 3). No undue significance should be attached to the excellent agreement between the experimental values of $Q$ and the value predicted for $Q_{\mathrm{cs}}$ by Escaig's model, nevertheless it is clear that the experimental data on the creep of copper in the lower temperature region are compatible with a dominant cross-slip-controlled mechanism. In the same way, it is obvious on figure 3 that the experimental data have been obtained in a very limited range of applied stresses so that, although it is possible to fit a straight line with $n=4.7$ to the data in the $\log \dot{\varepsilon}-\log \sigma$ plot, one could as well believe that $n=3$ for lower stresses and that the dependence is not linear for higher stresses, in other words there is no evidence that equation (13) would not represent the data as well.

4.3 HeXagonal close paCKed metals. - Creep experiments on hcp metals $(\mathrm{Mg}, \mathrm{Zn}, \mathrm{Cd})$ have also generally shown the existence of two temperature domains with different activation energies $([17,18,19$, 20, 21]). However, as already pointed out by Friedel [6], in this case it is the lower activation energy in the lower temperature region that can be fitted to $Q_{\text {SD. }}$. As in the case of aluminium, the observation of secondary prismatic slip traces and the existence of a theoretical model by Friedel [22] ascribing prismatic slip to the cross-slip of basal dislocations, led several authors to propose tentative explanations for the higher temperature domain in magnesium in terms of cross-slip controlled creep, ([17, 18]). Crossland and Jones also noted that an increase in stress exponent up to $n=10$ accompanied the transition to the high temperature mechanism. These conclusions can probably be extended to the other hep metals whose creep behavior could then be represented by a surface like the one in figure $2 b$. More generally, Friedel [6] suggested that cross-slip may account for the behavior of other materials with an activation energy which decreases with increasing stress.

4.4 A feW tentative Considerations. $-a$ ) The proposed model of creep controlled by climb and cross slip as two parallel-concurrent mechanisms has the advantage of giving a physical basis to the influence of the stacking fault energy on creep rate which up to now has been only described phenomenologically by relations such as : $\dot{\varepsilon} \propto \gamma_{\mathbf{F}}^{3.5}$ [13]. Mukherjee, Bird and Dorn [23], proposed instead without more physical justification that the stress exponent $n$ could depend on $\gamma_{F}$, increasing as $\gamma_{F}$ decreases.

If we agree to consider $n$ in most cases as only the slope of the straight line that fits best, in a limited stress range, the experimental points actually lying on a more complicated $\dot{\varepsilon}-\sigma$ curve, then the fact that $n$ increases with a decrease of $\gamma_{F}$ would simply mean that the contribution of cross-slip to the control of the creep rate increases which is to be expected if the stacking fault energy decreases.

b) Sherby and Burke [24] have empirically divided the solid solution alloys into the two following classes :

Class I, alloys, which are not influenced by $\gamma_{\mathrm{F}}$ and for which the stress exponent $n=3$.

Class II, alloys, which are influenced by changes in $\gamma_{F}$ and for which $n=5$.

It is suggested that in class I alloys cross slip is rendered completely impossible by extremely wide splitting of dislocations and/or segregation of impurities on the stacking fault. Climb could then entirely control $\dot{\varepsilon}$ with its natural exponent $n=3$, provided, of course that the creep rate is not controlled by viscous glide of dislocations. In class I alloys which behave as pure metals, cross-slip would still be possible although more difficult, with a higher $Q_{\mathrm{cs}}$ hence high values of $n$, in the transition range.

5. Conclusions. - i) A general model for recoverycontrolled high-temperature creep based on the operation of two parallel-concurrent recovery processes is proposed, which incorporates the following features :

a) The unblocking of edge dislocations by climb, with an activation energy equal to the activation energy for self-diffusion $Q_{\mathrm{SD}}$ and a power law stress dependence with $n=3$.

b) The unblocking of split screw dislocations, with a stress-dependent activation energy equal to the activation energy for cross-slip $Q_{\mathrm{cs}}$. The role of screw and edge dislocations thus becomes symmetrical and the creep rate can be written :

$\dot{\varepsilon}=\dot{\varepsilon}_{0, \mathrm{SD}}\left(\frac{\sigma}{\mu}\right)^{3} \exp -\frac{Q_{\mathrm{SD}}}{k T}+\dot{\varepsilon}_{0, \mathrm{CS}}\left(\frac{\sigma}{\mu}\right)^{2} \exp -\frac{Q_{\mathrm{CS}}\left(\sigma, \gamma_{\mathrm{F}}\right)}{k T}$.

ii) In a large range of temperature and applied stress, there should be one domain where climb is the dominant process and one where it is cross slip. The location of these two domains on the surface $\ln \dot{\varepsilon}=f(\ln \sigma, 1 / T)$ depends on the relative magnitude of $Q_{\mathrm{SD}}$ and $Q_{\mathrm{Cs}}$.

There is a transition domain where physically meaningless values of the activation energy and of the stress exponent $(n>3)$ may be fitted to the experi- 
mental data. This casts doubt on the validity of the procedure consisting of using the self-diffusion coefficient to normalize values of the creep rate obtained for different values of the temperature and the applied stress.

iii) As an example the published data for the creep of copper are reviewed. The data are found to be compatible with the operation of cross slip as a dominant process in the lower temperature range. It is suggested that the proposed model may account for the influence of stacking fault energy on creep rate, and for the existence of two classes of solid solution alloys.

iv) More theoretical studies of cross slip in various structures and calculations of cross slip activation energies are needed to make the present model quantitatively useful in determining the mechanisms of high temperature creep.

Acknowledgments : I gratefully thank Prof. J. Friedel for stimulating discussions which made me aware of the importance of cross-slip.

\section{References}

[1] Weertman, J., in John E. Dorn Memorial Symposium, Amer. Soc. Met. Metals Park, Ohio (1972).

[2] Muknerjee, A. K., in Treatise of Materials Science and Technology, R. J. Arsenault Ed.(Academic Press, N. Y.) tome 6 (1975) 163.

[3] PoIRIER, J. P., Plasticité à haute température des solides cristallins (Eyrolles Paris) 1976.

[4] Weertman, J., Trans. ASM 61 (1968) 681.

[5] Gifkins, R. C., J. Mater. Sci. 5 (1970) 156.

[6] FrIEdel, J., Dislocations (Pergamon Press) 1964.

[7] Escaig, B., J. Physique 29 (1968) 225.

[8] Stocker, R. L., and Ashby, M. F., Script Met. 7 (1973) 115.

[9] Sherby, O. D., Lytton, J. L. and Dorn, J. E., Acta Met. 5 (1957) 219.

[10] Lytton, J. L., Shepard, L. A. and Dorn, J. E., Trans AIME 212 (1958) 220.

[11] Dorn, J. E. and JAFFe, N., Trans. AIME 221 (1961) 229.

[12] Feltham, P. and Meakin, J. D., Acta Met. 7 (1959) 614.

[13] Barrett, C. R. and Sherby, O. D., Trans. AIME 230 (1964) 1322.

- Trans. AIME 233 (1965) 1116.
[14] Gilbert, E. R. and Munson, D. E., Trans. AIME 233 (1965) 429.

[15] Muehleisen, E. C., Shepard, L. A. and Dorn, J. E., Script. Met. 4 (1970), 995.

[16] Pahutova, M., ČADEK, J. and RYš, P., Phil. Mag. 23 (1971) 509.

[17] Tegart, W. J. M., Acta Met. 9 (1961) 614

[18] Crossland, I. G. and Jones, R. B., Met. Sci.J. 6 (1972) 162.

[19] Tegart, W. J. M. and Sherby, O. D., Phil. Mag. 5 (1958) 1287.

[20] Fuinn, J. E. and Munson, D. E., Phil. Mag. 10 (1964) 861.

[21] Flinn, J. E. and Duran, S. A., Trans AIME 236 (1966) 1056.

[22] Friedel, J., Internal stresses and Fatigue in metals, G. M. Rassweiler, W. L. Grube Eds (Elsevier) 1959 pp. 238-599.

[23] Mukherjee, A. K., Bird, J. E. and Dorn, J. E., Trans. AIME 62 (1969) 155.

[24] Sherby, O. D. and Burke, P. M., Progr. Mater. Sci. 13 (1967) 325. 